Session 2213

\title{
Virtual Reality Laboratory Accidents
}

\author{
John T. Bell, H. Scott Fogler \\ University of Illinois at Chicago / University of Michigan at Ann Arbor
}

\section{Background \& Introduction}

Every year there are far too many laboratory accidents, in undergraduate teaching labs, graduate research labs, industrial testing labs, medical labs, and others. These accidents continue to occur in spite of the most modern safety policies and training practices. Of course some accidents can never be avoided, but far too many occur because people have become complacent or forgetful of the safe procedures that they have been taught.

On the other hand, anyone who has ever experienced an accident is likely to remember that experience far longer than any set of written safety rules. Obviously we can't deliberately involve our students in real accidents just to emphasize the importance of safety, but we can let them experience virtual accidents, through the use of virtual reality, ( VR )[1-7]. These virtual accidents will not have the same impact as real accidents, but they will have a more long lasting effect than written rules on paper.

One of the major goals of this project is to create a series of virtual accidents that will have as broad an impact as possible on a world-wide scale. This goal implies delivering the simulations via the world wide web, either in the form of simulations runnable directly from the web or in the form of downloadable packages. A second goal is to explore and experiment with the different viable formats, to determine which is/are most applicable for this type of application, and also to reach a wider audience through multi-platform support.

The Virtual Reality Laboratory Accident project is currently being implemented by students in the Virtual Reality Undergraduate Projects Laboratory ( VRUPL ) at the University of Illinois at Chicago in conjunction with students from the Department of Chemical Engineering at the University of Michigan at Ann Arbor. This work extends and continues previous work done by the authors under the Virtual Reality in Chemical Engineering Laboratory ( VRiChEL) at the University of Michigan [8-13]. The VRiChEL web site ( including free downloads of completed simulations ) has been moved to UIC, where it is being maintained by VRUPLers as a sub-page of the VRUPL web site, http://www.vrupl.uic.edu. VRUPL has been set up as an undergraduate satellite to the graduate research Electronic Visualization Laboratory ( http://www.evl.uic.edu ) under the direction of Dr. Thomas Defanti, and receives both financial and technical support from that group, as well as enjoying a synergistic relationship with the graduate research projects, students, and seminars. 


\section{Site Layout}

A web site has been developed for the laboratory accidents project ( as a sub-page under http://www.vrupl.evl.uic.edu ) with the general layout shown in Figure 1. The main page introduces users to the site, describes the overall goals of the project, personnel, etc., and provides links to four sub pages. Two are logistical, and one is a page containing links to a broad range of external safety-related web sites, such as OSHA, NIOSH, MSDS repositories, etc.

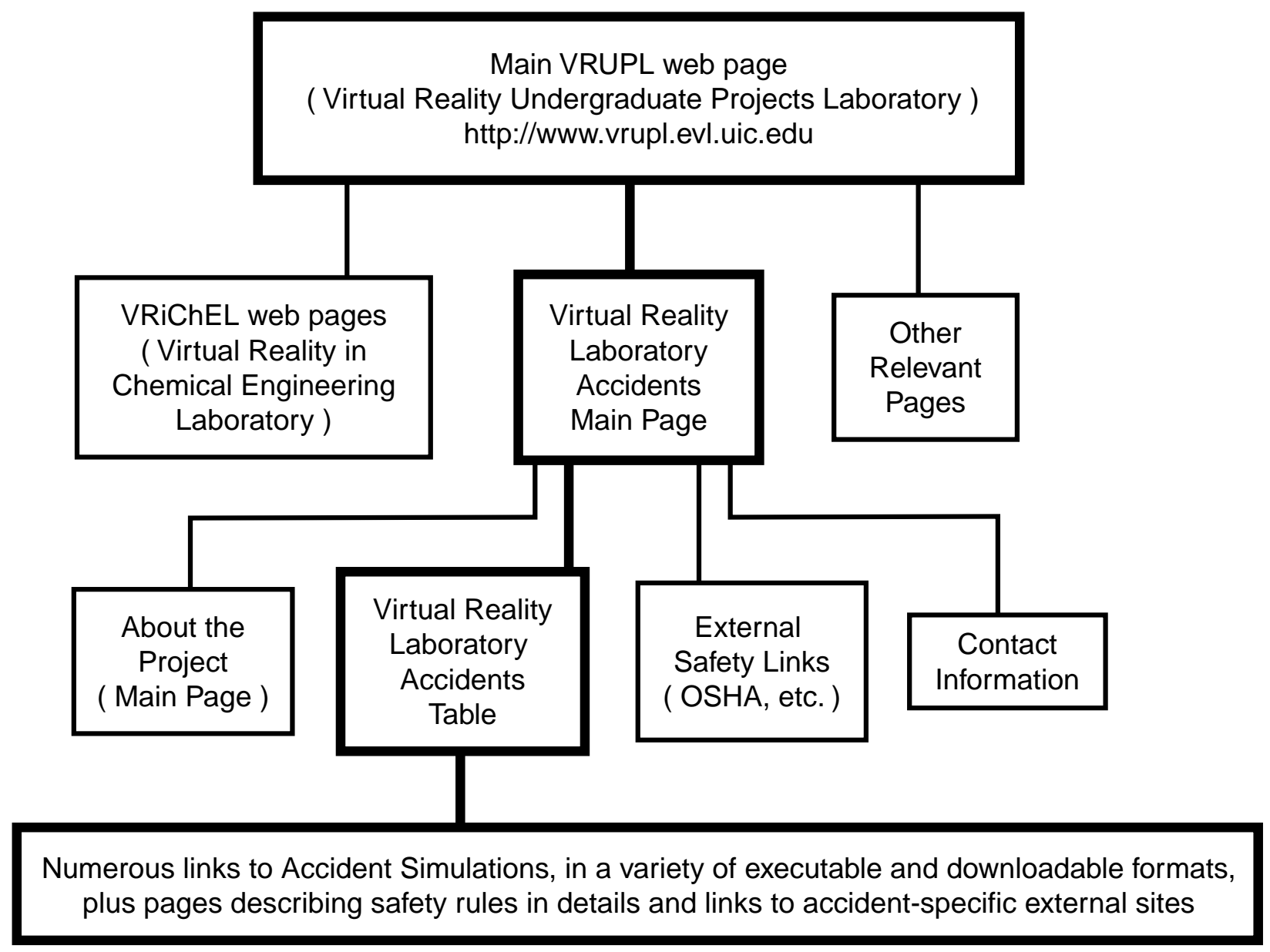

Figure 1: Virtual Lab Accidents Web Site Layout

The fourth main sub page leads to the accident simulations, through a table of related links. Each row of the table corresponds to a different safety rule or scenario, and the different columns of the table provide links to different simulation formats. The first column of the table states the rule for that row, and provides a link to a page discussing the rule in greater depth. Some of the simulation formats can be run directly from the web, and for these there is a concluding web page that provides feedback and links to the rule page and relevant external web sites (which are also linked from the rule page, whether or not the simulation format chosen runs from the web. ) 


\section{Formats Developed}

In accordance with the second major goal of this project, a number of different formats have been considered for development. In exploring these formats, there are several competing criteria to be considered:

- The desire to reach a wide audience by having simulations that run directly from the web, regardless of the users' computer hardware or operating system.

- The desire to produce VR simulation with high degrees of believability and realism, containing high level of detail, running at real-time speeds, and supporting a variety of VR-related hardware devices.

- Leveraging our efforts by producing different versions of the same simulations, thereby reaching multiple platforms with little additional effort.

- Exposing students to a variety of development environments and tools.

The following formats have either been implemented or are planned for future evaluation:

- VRML: The Virtual Reality Modeling Language, ( VRML ) [14, 15], is an extension to the standard HTML that provides for the description of, and interaction with, animated three-dimensional objects. The benefit of this format is that it is instantly available to anyone with the proper plug-in, directly over the web, and is ( theoretically) platform and browser independent. The down side is that it tends to be relatively slow, is not really as platform and browser independent as its proponents claim, and does not support the use of special VR hardware such as head-mounted displays ( yet ).

- Binary executable programs: We are using $\mathrm{C} / \mathrm{C}++$ programming and the WorldToolKit ( WTK ) software library from Sense8 corporation [16] to produce binary executable versions of many of the simulations. These run faster than VRML and support a variety of special devices, but are completely platform dependant and must be downloaded and installed on a user's computer before use. It is, however, relatively simple to produce multiple versions for different platforms, which we have done ( Windows NT, Windows 9X, Silicon Graphics Irix ).

- WorldUp: WorldUp is another product from Sense8 that utilizes a graphical development environment and Basic scripting instead of $\mathrm{C}$ programming. There is a plug-in available to run WorldUp programs directly from a web browser, and it also supports the use of VR hardware (WorldUp is based on WorldToolKit as the underlying engine. ) We have recently completed our first WorldUp simulation, and have not yet determined if special hardware is supported when running it via the web plug-in, but suspect not.

- Java3D: Java3D is a Java package that supports the description of, and interaction with, animated three-dimensional objects, either as a stand alone program or as a web applet [17]. This format is planned as a future area of exploration and development. 


\section{IV. "Completed" Simulations}

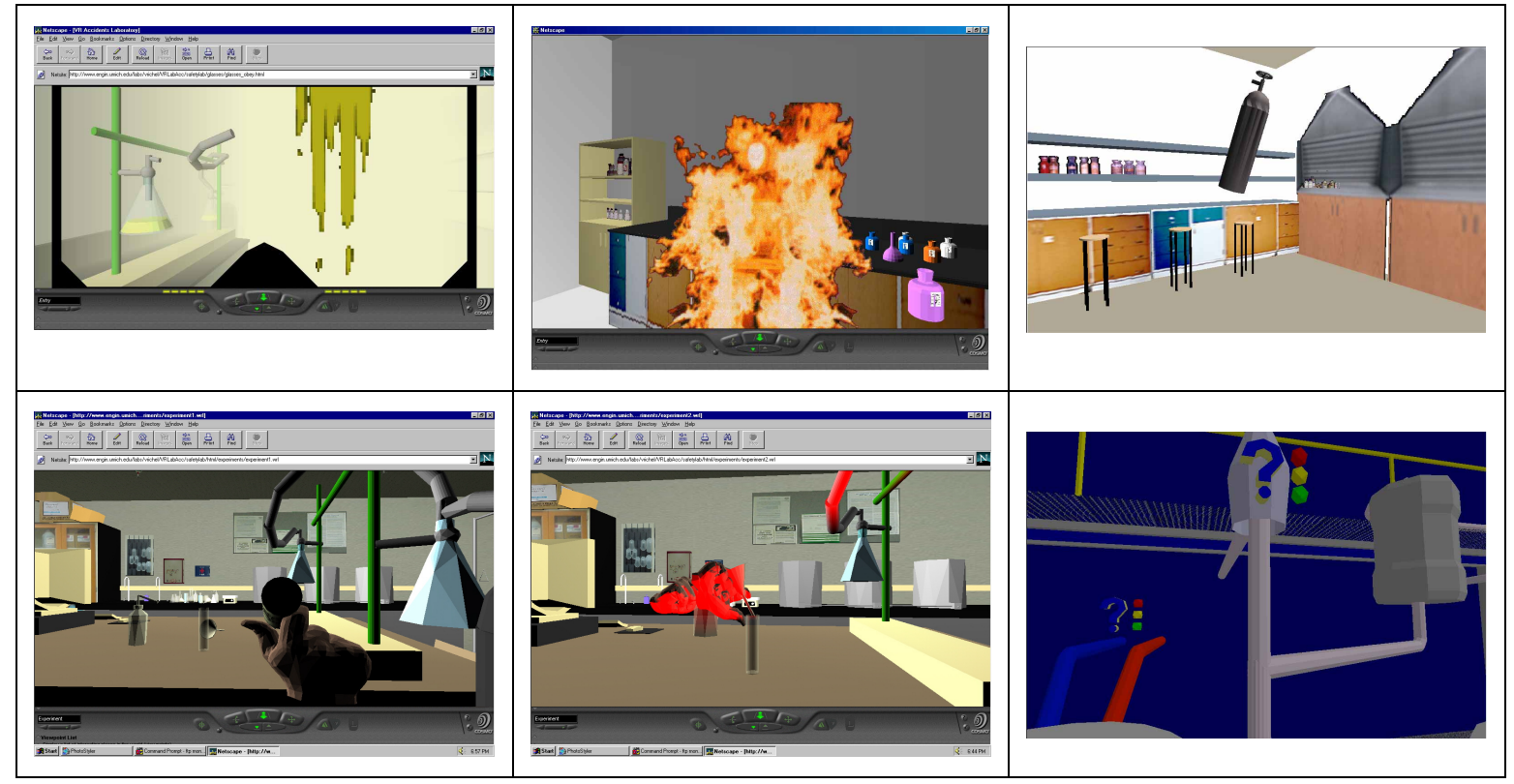

Figure 2: Scenes From Completed Simulations:

Top Row: a.) Safety Glasses. b.) Proper Storage. c.) Secure Gas Cylinders.

Bottom Row: d.) No Food or Drink. e.) Keep Aisleways Clear. f.) SafeHunt.

The following simulations have been completed as of January 2001, in at least their first draft and in at least one format. Some but not all of these have been placed on the web for public access.

- Always Wear Safety Glasses ( Figure 2a ): This was our first lab accident, and has now been completed in both VRML and WTK formats. Users choose whether to obey or disobey the rule, and then enter the lab. Approaching an experiment causes a hose to break loose, spraying the user and resulting in either dirty glasses or blindness. In the latter case the screen fades to red and then black, and the simulation freezes, emphasizing that there are no "do-overs" when eyesight is lost.

- Always Store Materials Properly ( Figure 2b ): This VRML simulation requires students to clean up a lab by moving items from the lab bench to their proper storage locations. If they do not clean up within a certain time, or if they store items improperly ( acids with bases, flammables outside of the flammables cabinet, etc. ), then the lab explodes with a fiery flash and a hair-raising scream.

- Securely Fasten Compressed Gas Cylinders ( Figure 2c ): This was our first use of the WorldUp format, and includes a compressed gas cylinder that is not securely fastened. As the user approaches, the nozzle breaks loose, turning the cylinder into a torpedo that proceeds to fly around the lab causing damage.

- No Food or Drink Allowed ( Figure 2d ): This VRML simulation involves a soda can sitting under a leaky hose. If the user disregards the rules and drinks from the can, then their view of the room spins before moving to face-up on the floor, and the 
screen fades to black. Discarding the can instead will result in a small trash fire and a concluding warning message ( future work ).

- Keep Aisleways Clear ( Figure 2e ): In this VRML simulation a small explosion occurs, requiring the user to exit the lab promptly before it fills with smoke. If they have followed the rule and kept the aisles clear, then they are able to get out on time, but if they have not, then they get stuck in the lab and die. This simulation includes graphic photos of an industrial accident victim whose injuries were partially caused by his inability to get out of a cluttered lab as quickly as his colleagues.

- SafeHunt ( Figure 2f ): This WTK simulation is not really a lab accident, but rather a safety analysis of a polyether polyol pilot plant, as described previously [11]. It is included on the VR Lab Accidents web site to increase its visibility and accessibility.

\section{Future Work}

The most significant future plan for this project is the development of a reactor accident simulation, in which students must design and operate a reactor properly in order to avoid an explosion. This simulation will be more extensive, requiring rigorous engineering calculations on the part of the students to ensure safe performance. In addition we intend to augment the existing pool of lab accidents with additional scenarios and formats, and to refine and improve all existing simulations.

\section{Conclusions}

A web site ( under http://www.vrupl.evl.uic.edu ) has been developed and populated with a number of virtual lab accidents in a variety of formats. It is believed that these accidents will have more impact on users than written rules, although not as much as real accidents. Continuing work includes additional simulations and the enhancement of current products.

\section{Acknowledgements}

The authors wish to gratefully acknowledge the efforts of the undergraduate student programmers who have assisted in the development of the modules described here, specifically Paul Sonda, Anita Sujarit, Scott Whitney, James Angelo, Candace Corea, Michael Cataletto, Rob King, Tim Mygatt, Michelle Westbrook, Sharon Ohba, Matthew Moersfelder, Petre Brotea, Adina Iclozan, Luis Bravo, Reem Baridi, David Analgate, Kelly McInnerny, and Joseph Fry ( in chronological order.) The VRUPL web site lists all students who have worked in the VRUPL and VRiChEL labs.

Technical Assistance has been provided by Dr. Joseph Louvar and Lawrence James of BASF Chemical Corporation, Tom Pakula and John Jechura of Marathon Oil Company, and Dan Crowl of Michigan Technological University. Funding for this project has come primarily from NSF grants \# DUE-9972302 and DUE-9555094. Additional funding and support for the VRUPL lab has been provided by Tom Defanti and the Electronic Visualization Laboratory ( http://www.evl.uic.edu ) at UIC, and from REU supplements to NSF grants \# 2-5-28007, 2-5-28905, 2-5-28933, and 2-5-28992. 


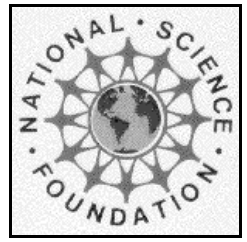

This project was supported, in part

by the

\section{National Science Foundation}

Opinions expressed are those of the authors

and not necessarily those of the Foundation

\section{Bibliographic Information}

1. Aukstakalnis, Steve and David Blatner, Silicon Mirage: The Art and Science of Virtual Reality, Peachpit Press, 1992.

2. Emerson, Toni and Debra Revere, "Virtual Reality in Training and Education: Resource Guide to Citations and Online Information", HITL Technical Publications, B-94-1 ( 1997 Revise ) 1994.

3. Larijani, L. Casey, The Virtual Reality Primer, McGraw Hill, 1994.

4. Pantelidis, Veronica S., "Virtual Reality and Education: Information Sources", ftp:ftp.hitl.washington.edu/pub/scivw/citations/VR-ED.html.

5. Pimental, Ken and Kevin Teixeira, Virtual Reality: Through the New Looking Glass. Second Edition, Windcrest Books, 1995.

6. Stampe, Dave, Bernie Roehl, and John Eagan, Virtual Reality Creations, The Waite Group Press, 1993.

7. Youngblut, Christine, "Educational Uses of Virtual Reality Technology", Technical Report IDA Document D-2128, 1998.

8. Bell, John T. and H. Scott Fogler, "Vicher: A Prototype Virtual Reality Based Educational Module for Chemical Reaction Engineering", Computer Applications in Engineering Education, 4(4), 1996.

9. Bell, John T. "Undergraduate Research Experiences Developing Virtual Reality Based Educational Modules". Proceedings of American Society for Engineering Education Annual Conference, Milwaukee, WI, American Society for Engineering Education, 1997.

10. Bell, John T. and H. Scott Fogler. "Virtual Reality in Chemical Engineering Education". Proceedings of 1998 North Central Sectional ASEE Conference, University of Detroit Mercy, American Society for Engineering Education North Central Section, 1998.

11. Bell, John and H. Scott Fogler. "A Virtual Reality Safety and Hazard Analysis Simulation". Proceedings of ASEE Annual Conference, St. Louis, MO, 2000.

12. Bell, John T. and H. Scott Fogler. "Virtual Reality in The Chemical Engineering Classroom". Proceedings of American Society for Engineering Education Annual Conference, Seattle, WA, American Society for Engineering Education, 1998.

13. Bell, John T. and H. Scott Fogler. "Virtual Laboratory Accidents Designed to Increase Safety Awareness". Proceedings of American Society for Engineering Education Annual Conference, Charlotte, NC, American Society for Engineering Education, 1999.

14. Carey, Rikk and Gavin Bell, The Annotated VRML 2.0 Reference Manual, AddisonWesley, 1997.

15. Consortium, Web 3D, http://www.vrml.org.

16. Sense8 Corporation, 100 Shoreline Highway, Suite 282, Mill Valley, CA 94941, (415) 331-6318, http://www.sense8.com.

17. Sowizral, Henry, Kevin Rushforth, and Michael Deering, The Java 3D API Specification, Second Edition. Second Edition, Addison Wesley. 653, 2000. 


\section{Biographical Information}

\section{John T. Bell}

Dr. John T. Bell holds degrees in Chemical Engineering and Computer Science, and is currently a Lecturer in the Department of EECS at the University of Illinois at Chicago. His research area is the application of interactive, immersive, 3-D computer display technology to the delivery and comprehension of scientific, engineering, and educational information. JBell@uic.edu, www.eecs.uic.edu / jbell, ( 312 ) 413-9054.

\section{H. Scott Fogler}

( Vennema Professor of Chemical Engineering, University of Michigan, Ann Arbor, ( 734 ) 763-1361, H.Scott.Fogler@umich.edu, www.engin.umich.edu / dept / cheme / fogler.html ) Dr. Fogler has over 150 research publications, including "The Elements of Chemical Reaction Engineering" ( the most used book on this subject in the world ) and "Strategies for Creative Problem Solving." He was the 1995 AIChE Warren K. Lewis award recipient for contributions to chemical engineering education. 